\title{
Frequency-Dependent Streaming Potential of Porous Media_Part 1: Experimental Approaches and Apparatus Design
}

\author{
P. W. J. Glover, ${ }^{1}$ J. Ruel, ${ }^{2}$ E. Tardif, ${ }^{2}$ and E. Walker ${ }^{1}$ \\ ${ }^{1}$ Department of Geology and Engineering Geology, Université Laval, Québec, QC, Canada G1V 0A6 \\ ${ }^{2}$ Department of Mechanical Engineering, Université Laval, Québec, QC, Canada G1V 0A6 \\ Correspondence should be addressed to P. W. J. Glover, paglover@ggl.ulaval.ca
}

Received 3 June 2011; Revised 21 October 2011; Accepted 12 December 2011

Academic Editor: Tsuneo Ishido

Copyright ( 2012 P. W. J. Glover et al. This is an open access article distributed under the Creative Commons Attribution License, which permits unrestricted use, distribution, and reproduction in any medium, provided the original work is properly cited.

\begin{abstract}
Electrokinetic phenomena link fluid flow and electrical flow in porous and fractured media such that a hydraulic flow will generate an electrical current and vice versa. Such a link is likely to be extremely useful, especially in the development of the electroseismic method. However, surprisingly few experimental measurements have been carried out, particularly as a function of frequency because of their difficulty. Here we have considered six different approaches to make laboratory determinations of the frequencydependent streaming potential coefficient. In each case, we have analyzed the mechanical, electrical, and other technical difficulties involved in each method. We conclude that the electromagnetic drive is currently the only approach that is practicable, while the piezoelectric drive may be useful for low permeability samples and at specified high frequencies. We have used the electro-magnetic drive approach to design, build, and test an apparatus for measuring the streaming potential coefficient of unconsolidated and disaggregated samples such as sands, gravels, and soils with a diameter of $25.4 \mathrm{~mm}$ and lengths between $50 \mathrm{~mm}$ and $300 \mathrm{~mm}$.
\end{abstract}

\section{Introduction}

While there are a growing number of streaming potential measurements on rocks and other porous media that are made with constant fluid flow, there are surprisingly few available for flow that varies in time. This is probably because such measurements have been considered very difficult to carry out. However, such measurements are likely to be of great importance in a number of fields, not least in the understanding and development of the seismoelectric exploration method.

The few previous measurements can be classified into two groups: (i) transient measurements with a percussive source and (ii) harmonic measurements with a vibrating source. The first of these approaches mimics many of the possible applications more closely, while the latter is capable of providing higher-quality frequency-specific data.

The percussive source studies measure transient electrokinetic processes in sand columns that arise when a controlled impact is made on a column of saturated sand [1-3]. These are difficult studies that require the impact to be repeatable and the seismoelectric and/or seismomagnetic conversion to be measured. Such transient measurements have confirmed the presence of seismo-electrokinetic and seismo-electromagnetic phenomena at high frequencies. However, the percussive seismic source does not produce a single frequency, so it cannot be used to measure the coupling coefficients as a function of frequency. Although it should be possible to examine the Fourier components of the seismic impact and the measured electric and magnetic signals in order to extract more specific information about the frequency dependence of the coupling coefficients [4], a pilot study in our laboratory indicated that such a process would be extremely difficult to carry out.

One would expect that a better approach would be to arrange a harmonically varying fluid flow at a specific frequency and then to measure the streaming potential and the fluid pressure difference from which a streaming potential coefficient at that frequency could be calculated. Repeating the experiment at different, well-defined frequencies should then allow the variation of the streaming potential coefficient as a function of frequency to be obtained. There have been only a few experiments using this approach. These experiments have made measurements on only 5 glass 
capillaries, one fritted glass filter, and 2 ceramic filters [5-9]. Only one rock has ever been measured at frequencies greater than $100 \mathrm{~Hz}$ - a Boise sandstone with $35 \%$ porosity [8].

The first measurements were made by Packard [5] using a cell with two rubber membranes and two platinum electrodes that was mounted on a reservoir. A "geophonetype push-pull driver" provided a harmonic signal to the reservoir while a single hydrophone measured the driving fluid pressure. In this cell the pressure measurement and streaming potential measurements are not colocated which may lead to systematic errors in the calculated streaming potential coefficient. Packard measured 4 glass capillary tubes in the frequency range $20 \mathrm{~Hz}$ to $200 \mathrm{~Hz}$ and developed a theoretical model to describe his results. Cooke [6] seems to have used a similar apparatus to that of Packard [5]. $\mathrm{He}$ obtained measurements on three fritted glass filters and two capillaries. Unfortunately, data from only one of the fritted glass filters is of sufficient quality to compare with other measurements; the other measurements are either not reported or cover an insufficiently large frequency range to calculate a transition frequency. However, Cooke [6] did show that measurements could be made up to $400 \mathrm{~Hz}$.

Sears and Groves [7] used chemical glassware as input and output reservoirs. Platinum electrodes were placed in each of the reservoirs and a steady-state pressure transducer was used to measure the fluid pressure. While a steady-state pressure transducer is not suitable for such an application, the low frequencies attained by Sears and Groves $(0.385 \mathrm{~Hz}$ to $21.28 \mathrm{~Hz}$ ) probably ensure that the pressure measurements are close to the real values. Sears and Groves used a piston that was driven by a scotch yoke. We examine this method and conclude that it can only be used up to $33 \mathrm{~Hz}$ with current technology. Unfortunately, while Sears and Groves measured capillary tubes of three different diameters, they only show frequency-dependent data for one.

More recently [8,9], a higher-quality experimental approach has used an electromechanical shaker as the source of the vibration and a rubber diaphragm, while nonpolarisable $\mathrm{Ag} / \mathrm{AgCl}$ electrodes were used to measure the streaming potential and miniature hydrophones were used to measure the fluid pressures. While these studies seem to be of high quality, unfortunately this apparatus was only used to measure a few samples, specifically 2 diameters of capillary tube [9], 2 porous filters [9], and a single sample of Boise sandstone [8] over the range $1 \mathrm{~Hz}$ to $500 \mathrm{~Hz}$.

For completeness it should be noted that measurements have also been made by Pengra et al. [10] up to about $100 \mathrm{~Hz}$, while Sheffer et al. [11] have published a design for measuring the streaming potential of soils but only for frequencies less than $0.5 \mathrm{~Hz}$.

The lack of data is associated with the experimental difficulties that such a measurement presents. This paper is the first of two linked papers. It seeks to explore the conceptual design of apparatuses that may be used to make frequencydependent streaming potential coefficient measurements and to describe one such apparatus that has been constructed to measure unconsolidated and disaggregated porous media. The second paper [12] presents some of the initial data that the apparatus has provided and explores how that data compares with a number of theoretical models that have been proposed to describe AC streaming potential coefficients.

\section{Frequency-Fluid Pressure Difference-Pore Size Relationships}

Since high-quality streaming potential measurements can be made in the millivolt range and most porous media have streaming potential coefficients that vary between $1 \mathrm{mV} / \mathrm{MPa}$ and several hundred $\mathrm{mV} / \mathrm{MPa}$, we need to be able to generate a pressure difference across the sample in the order of megapascals. This section examines how the pressure difference $\Delta P(\omega)$ depends upon the length of the sample $(L)$, the dynamic viscosity of the fluid $\left(\eta_{f}\right)$, the density of the fluid $\left(\rho_{f}\right)$, the piston displacement driving the fluid $(d)$, the frequency of the driving force $(\omega)$, and the effective pore size of the sample material that we take to be equal to the radius of a capillary tube $(r)$ in the first instance.

The mean flow velocity $v(\omega)($ in $\mathrm{m} / \mathrm{s})$ in a capillary tube of radius $r$ in the AC regime (with an angular frequency $\omega$ ) is given by Johnson et al. [13] and Reppert et al. [9] and can be calculated easily from the work of Bernabé [14] as

$$
v(\omega)=\frac{\Delta P(\omega)}{\eta_{f} L k^{2}}\left(\frac{2}{k r} \frac{J_{1}(k r)}{J_{0}(k r)}-1\right), \quad \text { where } k=\sqrt{\frac{-i \omega \rho_{f}}{\eta_{f}}}
$$

The AC permeability $\kappa_{\mathrm{AC}}$ can then be calculated to be

$$
\kappa_{\mathrm{AC}}(\omega)=\frac{\eta_{f} L}{\Delta P(\omega)} v(\omega)=\frac{1}{k^{2}}\left[\frac{2}{k r} \frac{J_{1}(k r)}{J_{0}(k r)}-1\right],
$$

which is consistent with Bernabé [14-16] and Charlaix et al. [17].

The limit of (2) as $\omega \rightarrow 0$ is simply $r^{2} / 8$, which is consistent with the steady-state permeability of a tube with radius $r$ given by Poiseuille's law $\kappa_{\mathrm{DC}}=\pi r^{4} / 8 A_{\text {tube }}$ for a single tube, where $A_{\text {tube }}=\pi r^{2}$. We can use (1) to derive an expression for the fluid pressure difference

$$
\Delta P(\omega)=v(\omega) \eta_{f} L k^{2}\left(\frac{2}{k r} \frac{J_{1}(k r)}{J_{0}(k r)}-1\right)^{-1} .
$$

The frequency-dependent fluid velocity and pressure difference are not linear functions of frequency and are not simple to calculate. However, we do not need to calculate the pressure difference as a function of frequency in order to constrain the design of the pressure cell and to choose the fluid pressure transducers. What we need is the maximum pressure difference as a function of frequency, porosity, sample length, piston displacement, and fluid properties (density and viscosity).

If we assume that the sample is completely saturated with the process fluid and is incompressible, we can define a maximum mean velocity within the sample as

$$
v_{\max }=\frac{d f}{\phi} \frac{A_{p}}{A},
$$




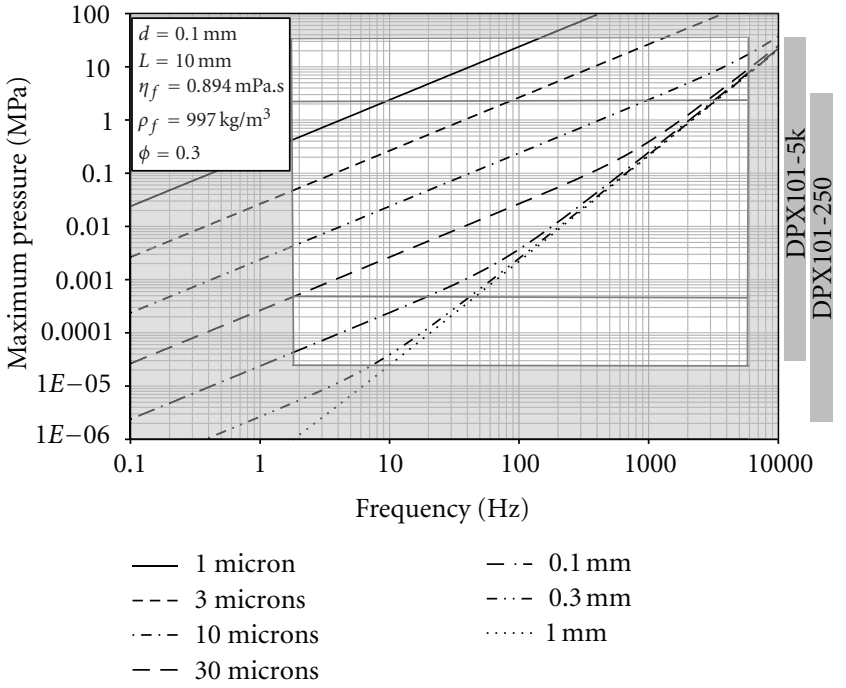

(a)

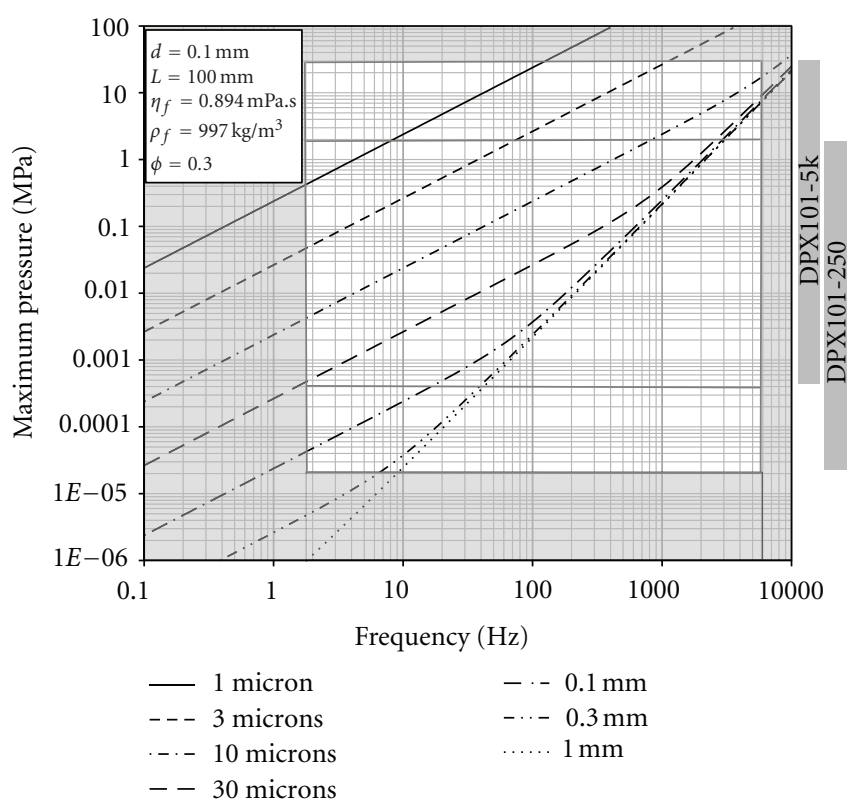

(c)

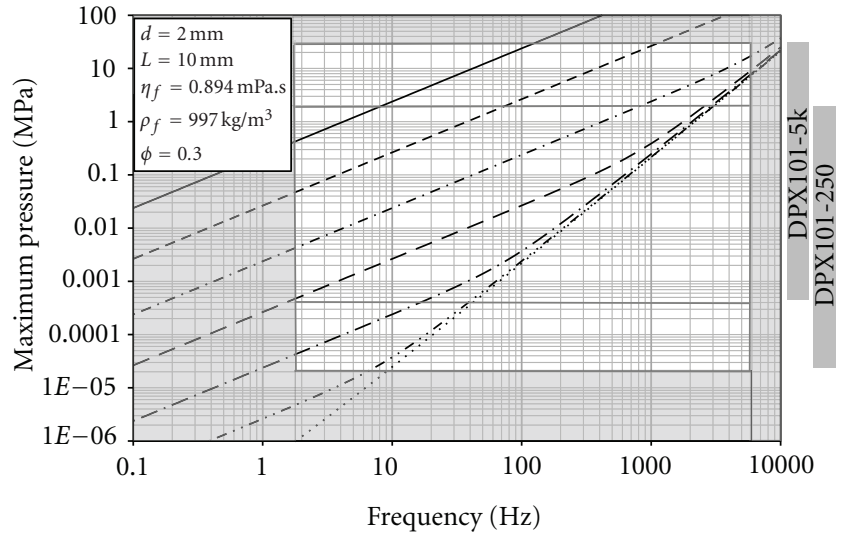

- 1 micron
---3 microns
.--10 microns
--30 microns

$-\cdot-0.1 \mathrm{~mm}$
$-\cdots-0.3 \mathrm{~mm}$
$\ldots .1 \mathrm{~mm}$

(b)

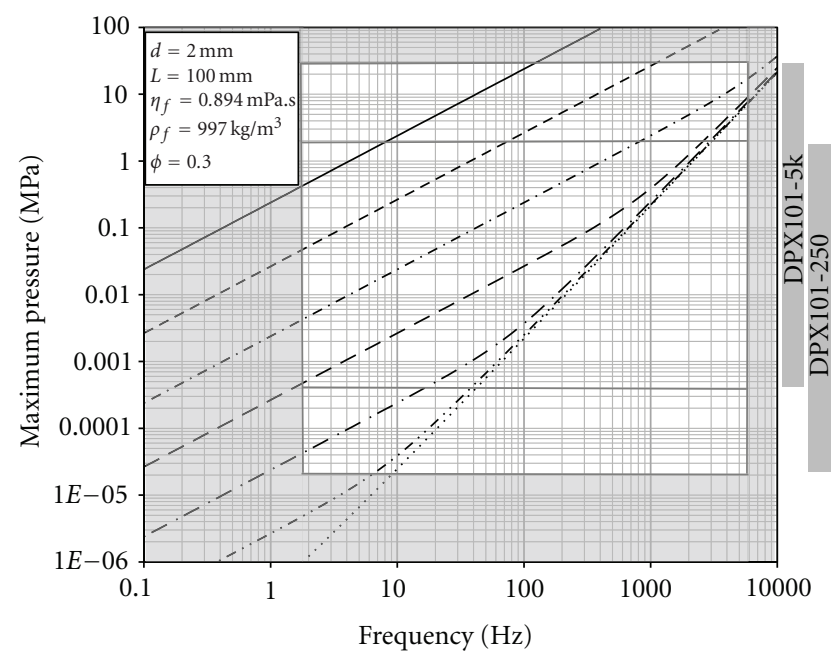

--3 microns $\quad-\cdots-0.3 \mathrm{~mm}$

30 micron

(d)

FIGURE 1: The maximum pressure difference generated by flowing an aqueous fluid through a porous medium using a harmonic piston. Imposed piston frequency (from 0.1 to $\left.10^{4} \mathrm{~Hz}\right), \phi=0.3$, sample length $L$ (10 and $100 \mathrm{~mm}$ ) and piston displacement $d(0.1 \mathrm{~mm}$ and $2 \mathrm{~mm}$ ), with the fluid parameters $\eta_{f}=8.96 \times 10^{-4} \mathrm{~Pa}$.s and $\rho_{f}=997 \mathrm{~kg} / \mathrm{m}^{3}$, which correspond to a $10^{-3} \mathrm{~mol} / \mathrm{L}$ solution of $\mathrm{NaCl}$ at $25^{\circ} \mathrm{C}$.

where $\phi$ is the sample porosity, $d$ is the piston displacement, $A_{p}$ is the area of the piston, $A$ is the area of the sample, and $\omega=2 \pi f$. Substituting (4) into (3) allows us to calculate the maximum pressure difference across the sample

$$
\Delta P_{\max }=\frac{d f}{\phi} \frac{A_{p}}{A} \eta_{f} L k^{2}\left(\frac{2}{k r} \frac{J_{1}(k r)}{J_{0}(k r)}-1\right)^{-1} .
$$

We have implemented (5) in Figure 1 for a sample with a porosity of 0.3 , a range of pore sizes, two values of piston displacement, and two values of sample length. In this figure the grey areas represent conditions that fall outside the specifications of the instruments that we are planning to construct. The minimum frequency $(2 \mathrm{~Hz})$ and maximum frequency $(6.5 \mathrm{kHz})$ are those defined by the electromagnetic shaker that we have subsequently used in our experimental apparatus. There are a limited number of pressure transducers on the market that can measure signals varying at high frequencies. The ranges of two of these transducers are shown on the right-hand side of each of the parts of the figure as grey bars. The specifications of the transducers are discussed in greater detail in Section 5.

Figure 1(a) shows that it is possible to make measurements in the frequency range $2 \mathrm{~Hz}<f<1000 \mathrm{~Hz}$ on samples 
TABLE 1: Specifications of an apparatus for making frequency-dependent streaming potential coefficient measurements.

\begin{tabular}{|c|c|c|c|c|}
\hline Characteristic & Unit & Min. & Max. & Comment \\
\hline Frequency & $\mathrm{Hz}$ & 2 & $1000(6500)$ & VTS-100 EM shaker (max. shaker spec. in parentheses) \\
\hline Piston displacement & $\mathrm{mm}$ & 0.1 & 22 & VTS-100 EM shaker \\
\hline Piston position precision & $\mathrm{mm}$ & \multicolumn{2}{|c|}{ \pm 0.05} & LVDT LD610-15 (Omega) \\
\hline \multirow{2}{*}{ Dynamic pressure measurement } & \multirow{2}{*}{$\mathrm{MPa}(\mathrm{psi})$} & \multicolumn{2}{|c|}{$1.72(250)$} & DPX101-250 dynamic pressure transducer (Omega) \\
\hline & & \multicolumn{2}{|c|}{$34.47(5000)$} & DPX101-5K dynamic pressure transducer (Omega) \\
\hline \multirow{2}{*}{$\begin{array}{l}\text { Pressure transducer proof } \\
\text { pressure }\end{array}$} & \multirow{2}{*}{$\mathrm{MPa}$} & \multicolumn{2}{|c|}{34.5} & DPX101-250 dynamic pressure transducer (Omega) \\
\hline & & \multicolumn{2}{|c|}{103.4} & DPX101-5K dynamic pressure transducer (Omega) \\
\hline \multirow{2}{*}{ Pressure transducer noise floor } & \multirow{2}{*}{$\mathrm{MPa}$} & \multicolumn{2}{|c|}{$27.6 \times 10^{-6}$} & DPX101-250 dynamic pressure transducer (Omega) \\
\hline & & \multicolumn{2}{|c|}{$482.6 \times 10^{-6}$} & DPX101-5K dynamic pressure transducer (Omega) \\
\hline \multirow{2}{*}{$\begin{array}{l}\text { Pressure transducer frequency } \\
\text { range }\end{array}$} & \multirow{2}{*}{$\mathrm{Hz}$} & 0.08 & $1.7 \times 10^{5}$ & DPX101-250 dynamic pressure transducer (Omega) \\
\hline & & 0.003 & $1.7 \times 10^{5}$ & DPX101-5K dynamic pressure transducer (Omega) \\
\hline \multirow{2}{*}{ Pressure rise time } & \multirow{2}{*}{$\mu \mathrm{s}$} & & 1 & DPX101-250 dynamic pressure transducer (Omega) \\
\hline & & & 1 & DPX101-5K dynamic pressure transducer (Omega) \\
\hline \multirow{2}{*}{$\begin{array}{l}\text { Pressure transducer resonant } \\
\text { frequency }\end{array}$} & \multirow{2}{*}{$\mathrm{MHz}$} & & 0.5 & DPX101-250 dynamic pressure transducer (Omega) \\
\hline & & & 0.5 & DPX101-5K dynamic pressure transducer (Omega) \\
\hline \multirow{2}{*}{$\begin{array}{l}\text { Pressure transducer maximum } \\
\text { frequency }\end{array}$} & \multirow{2}{*}{$\mathrm{MHz}$} & \multicolumn{2}{|c|}{0.17} & DPX101-250 dynamic pressure transducer (Omega) \\
\hline & & \multicolumn{2}{|c|}{0.17} & DPX101-5K dynamic pressure transducer (Omega) \\
\hline $\begin{array}{l}\text { Pressure transducer preamp input } \\
\text { impedance }\end{array}$ & $\Omega$ & \multicolumn{2}{|c|}{$10^{12}$} & TL074IN J-FET input operational amplifiers \\
\hline Electrode preamp input impedance & $\Omega$ & \multicolumn{2}{|c|}{$10^{12}$} & TL074IN J-FET input operational amplifiers \\
\hline Preamplification slew rate & $\mathrm{V} / \mu \mathrm{s}$ & \multicolumn{2}{|c|}{13} & TL074IN J-FET input operational amplifiers \\
\hline $\begin{array}{l}\text { Maximum preamplification } \\
\text { frequency }\end{array}$ & $\mathrm{MHz}$ & - & 4.83 & $\begin{array}{l}\text { TL074IN J-FET, assuming maximum amplified signal is } \\
10 \mathrm{~V}\end{array}$ \\
\hline Streaming potential measurement & $\mathrm{mV}$ & $5 \times 10^{-2}$ & $10^{4}$ & $\begin{array}{l}\text { Min. set by the noise floor. Max. limited by the preamp. } \\
\text { circuits }\end{array}$ \\
\hline \multirow{2}{*}{ Streaming potential constant } & \multirow{2}{*}{$\mathrm{mV} / \mathrm{MPa}$} & 0.029 & 5800 & DPX101-250 dynamic pressure transducer (Omega) \\
\hline & & 0.00145 & 290 & DPX101-5K dynamic pressure transducer (Omega) \\
\hline \multirow{2}{*}{ Sample length } & \multirow{2}{*}{$\mathrm{cm}$} & 0.5 & 2 & For rocks and clayey soils \\
\hline & & 5 & 30 & For sands and gravels and clay-free soils \\
\hline \multirow{2}{*}{ Sample diameter } & \multirow{2}{*}{$\mathrm{cm}$} & 1 & 1 & For rocks and clayey soils \\
\hline & & 2.54 & 2.54 & For sands and gravels and clay-free soils \\
\hline Temperature range & ${ }^{\circ} \mathrm{C}$ & -70 & 120 & Defined by the pressure transducers \\
\hline
\end{tabular}

with a length of $10 \mathrm{~mm}$, a porosity of 0.3 , and characteristic pore sizes in the range $1 \times 10^{-6} \mathrm{~m}<r_{\text {pore }}<3 \times 10^{-5} \mathrm{~m}$ using either type of transducer and a piston displacement of $0.1 \mathrm{~mm}$. This range seems rather restrictive. However, the displacement of the piston can be controlled and increased up to $22 \mathrm{~mm}$, allowing the measureable range of pore sizes to be extended to $1 \times 10^{-6} \mathrm{~m}<r_{\text {pore }}<1 \times 10^{-3} \mathrm{~m}$. Figure 1(b) shows the maximum pressure for a piston displacement of $2 \mathrm{~mm}$ for comparison. This range covers the normal range of pore sizes found in reservoir rocks.

If the porous material is disaggregated, such as sand the sample permeability is often lower and longer samples may be used. Figure 1(c) shows the results for a sample with a length of $100 \mathrm{~mm}$ and a porosity of 0.3 . The range of pore sizes which can be measured is now restricted to $3 \times 10^{-5} \mathrm{~m}<r_{\text {pore }}<1 \times 10^{-3} \mathrm{~m}$ by using piston displacements in the range $0.1 \mathrm{~mm}-2 \mathrm{~mm}$ (Figure $1(\mathrm{~d})$ ), which poses no real problems for sands and gravels which generally do not contain micropores. It would, however, be a restriction on the measurement of soils which may contain smaller pores than 10 microns that are associated with clays.

\section{General Specifications}

We aim to design an apparatus for measuring the streaming potential of porous media as a function of frequency for the greatest range of frequency, porosity, permeability, and sample size possible. We have shown in the previous section that these parameters are mutually dependent, which leads to compromises in the specifications. Table 1 shows the specifications at which we have arrived for the apparatus described in this work, the details of which are discussed in the following section.

A minimum frequency of $2 \mathrm{~Hz}$ has been specified, which is the lower limit of the electromagnetic shaker that was available to us during testing (VTS-100). The maximum 
limit of this shaker is $6.5 \mathrm{kHz}$. However, a maximum frequency of $1 \mathrm{kHz}$ was specified for the following reason. Figure 1 shows that if we use a DPX101-250 dynamic pressure transducer, for which the maximum fluid pressure is $250 \mathrm{psi}(1.724 \mathrm{MPa})$, it is possible to make measurements on samples up to $10 \mathrm{~mm}$ long with a piston displacement of $0.1 \mathrm{~mm}$, a porosity of 0.3 , and pore radii larger than 3 microns, or with pore radii greater than 30 microns if a $2 \mathrm{~mm}$ piston displacement is used. If a longer sample is used (say $100 \mathrm{~mm}$ ), measurements may be made on porous media with pore radii greater than 10 microns for a $0.1 \mathrm{~mm}$ piston displacement and greater than 100 microns for a piston displacement of $2 \mathrm{~mm}$. It is clear therefore that apparatuses for rock samples should be designed to take small samples so that the piston displacement may be sufficiently large to be controlled accurately, whereas apparatuses for unconsolidated samples of sands and gravels, which tend to have larger porosities and pore radii can be designed to use larger samples.

We should also consider the theoretical relationship between transition frequency and characteristic sample pore radius $[18]$

$$
\omega_{t}=\frac{\phi}{\tau_{e} \kappa_{\mathrm{DC}}} \frac{\eta_{f}}{\rho_{f}}=\frac{8}{r_{\mathrm{eff}}^{2}} \frac{\eta_{f}}{\rho_{f}},
$$

where $\eta_{f}$ (Pa.s) is the dynamic viscosity of the fluid, $\rho_{f}$ $\left(\mathrm{kg} / \mathrm{m}^{3}\right)$ is the density of the bulk fluid, $\tau_{\mathrm{e}}$ (unitless) is the electrical tortuosity of the pore network, $\phi$ (unitless) is the porosity of the sample, $\kappa_{\mathrm{DC}}\left(\mathrm{m}^{2}\right)$ is the steady-state fluid permeability, and $r_{\text {eff }}(\mathrm{m})$ is the effective pore radius of the rock. The parameter $\omega_{t}(\mathrm{rad} / \mathrm{s})$ is the transition frequency, at which the quadrature component of the dispersive system is greatest $[18,19]$.

If we specify a maximum frequency of $1 \mathrm{kHz},(6)$ implies that we are able to measure samples with hydraulically conductive pores greater than $33.8 \mu \mathrm{m}$ (using a typical aqueous pore fluid with $\rho_{f}=997 \mathrm{~kg} / \mathrm{m}^{3}$ and $\eta_{f}=8.94 \times$ $10^{4}$ Pa.s). Reference to Figure 1 (b) shows that this criterion is met for a piston displacement of $2 \mathrm{~mm}$. Samples with larger pores may use larger piston displacements up to about $22 \mathrm{~mm}$, which is the limit of the VTS-100 electromechanical shaker, while samples with smaller pores (or larger lengths) can use smaller piston displacements or use a higher-range pressure transducer (the DPX101-5 K has a maximum pressure of 5000 psi, i.e., $34.474 \mathrm{MPa}$ ). The higher range transducer would be preferable from the point of view of data quality. These initial specifications also allow us the possibility of extending the frequency range to $6.5 \mathrm{kHz}$ for samples with large pores if we install pressure transducer with the higher range.

The maximum and minimum physical limits to the piston displacement are defined by the electromagnetic shaker as discussed in the appendix. However, the practical lower limit is controlled by (i) our ability to distinguish a measureable streaming potential from the background noise and (ii) the resolution of the LVDT that measures the position of the piston $( \pm 50 \mu \mathrm{m})$.

Since a streaming potential will be generated and measured, we have specified that the sample cell is made of insulating material such that the only counter current is that generated within the sample. It is equally important that no part of the cell, driver, fluid, or fluid tanks acts as an antenna in order to reduce electrical noise. Since the apparatus is to be used with a range of fluid salinities $\left(10^{-6}-2 \mathrm{~mol} / \mathrm{L}\right)$ and $\mathrm{pH}(4-11)$, it is important that its wetted parts are sufficiently resistant to corrosion.

\section{Experimental Design}

There are three main aspects of the design. These are as follows.

(1) The design of a pressure vessel that accommodates a moveable piston, and in which the sample is held within a tube or a sleeve such that the fluid may be pushed through it. A number of standard pressure vessel designs can be used. We prefer a simple Perspex tube for unconsolidated samples and a modified Haskel Cell-type vessel for solid samples.

(2) The design of transducer and electrode assemblages to measure and log the data at the required frequencies. These are described in Section 5.

(3) The design of a mechanism to drive fluids through the sample at the required frequencies. There are many ways of driving the cell, all of which are discussed in detail below and in the appendix.

We considered several methods of creating an alternating flow of fluid through a porous sample, which can be categorised as follows: (i) mechanical drive using a connecting pin (Figure 2(a)) or a cam (Figure 2(b)), (ii) pneumatic drive (Figure 3(a)), (iii) hydraulic drive, (iv) electromagnetic drive (Figure 3(b)), and (v) piezoelectric coupling. We have examined all six methods in this paper giving a detailed analysis in the appendix and summarising the main findings below and listing the main advantages and disadvantages of each method in Table 2 for easy comparison.

In summary, the hydraulic drive was discounted at an early stage because it is very difficult to drive hydraulic fluid at high frequencies. Four of the remaining five approaches were discounted because they are not capable of providing a well-controlled dynamic fluid flow up to $1 \mathrm{kHz}$. For the connecting-pin (sometimes called "scotch yoke") and the cam designs, neither a motor with a combination of sufficient torque and speed, nor a spring with sufficient stiffness per mass is currently available in order for frequencies up to $1 \mathrm{kHz}$ to be reached. Such systems would be possible, but could attain frequencies only up to about $33 \mathrm{~Hz}$ with current technology. A pneumatic actuator approach can only be used to $100 \mathrm{~Hz}$, which represents the maximum speed of the fastest servovalves that are presently available. A piezoelectric drive was rejected as it is very difficult to vary the frequency, and equally difficult to provide sufficient piston displacement. The electromagnetic shaker design was clearly the best choice as a dynamic drive. 


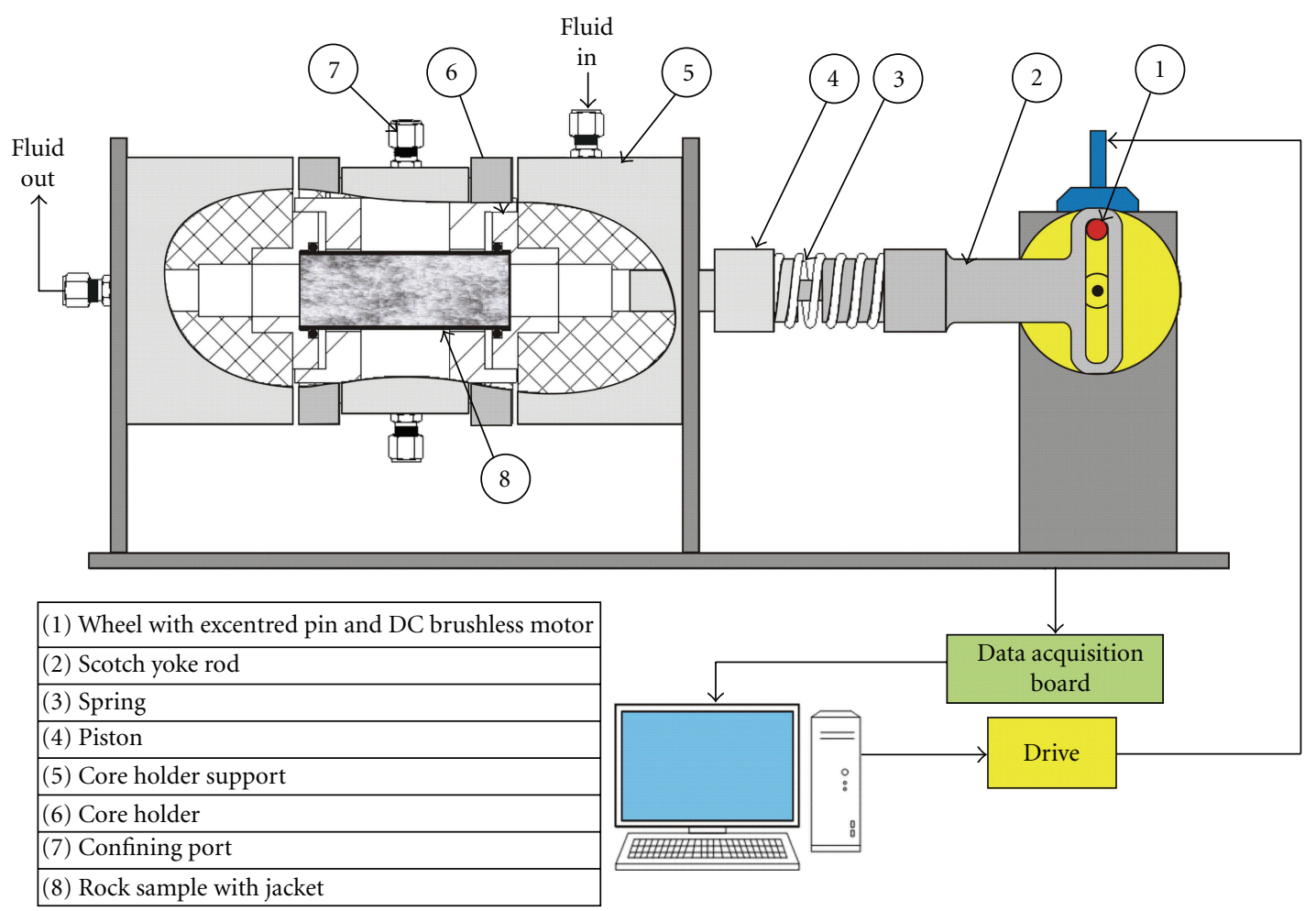

(a)

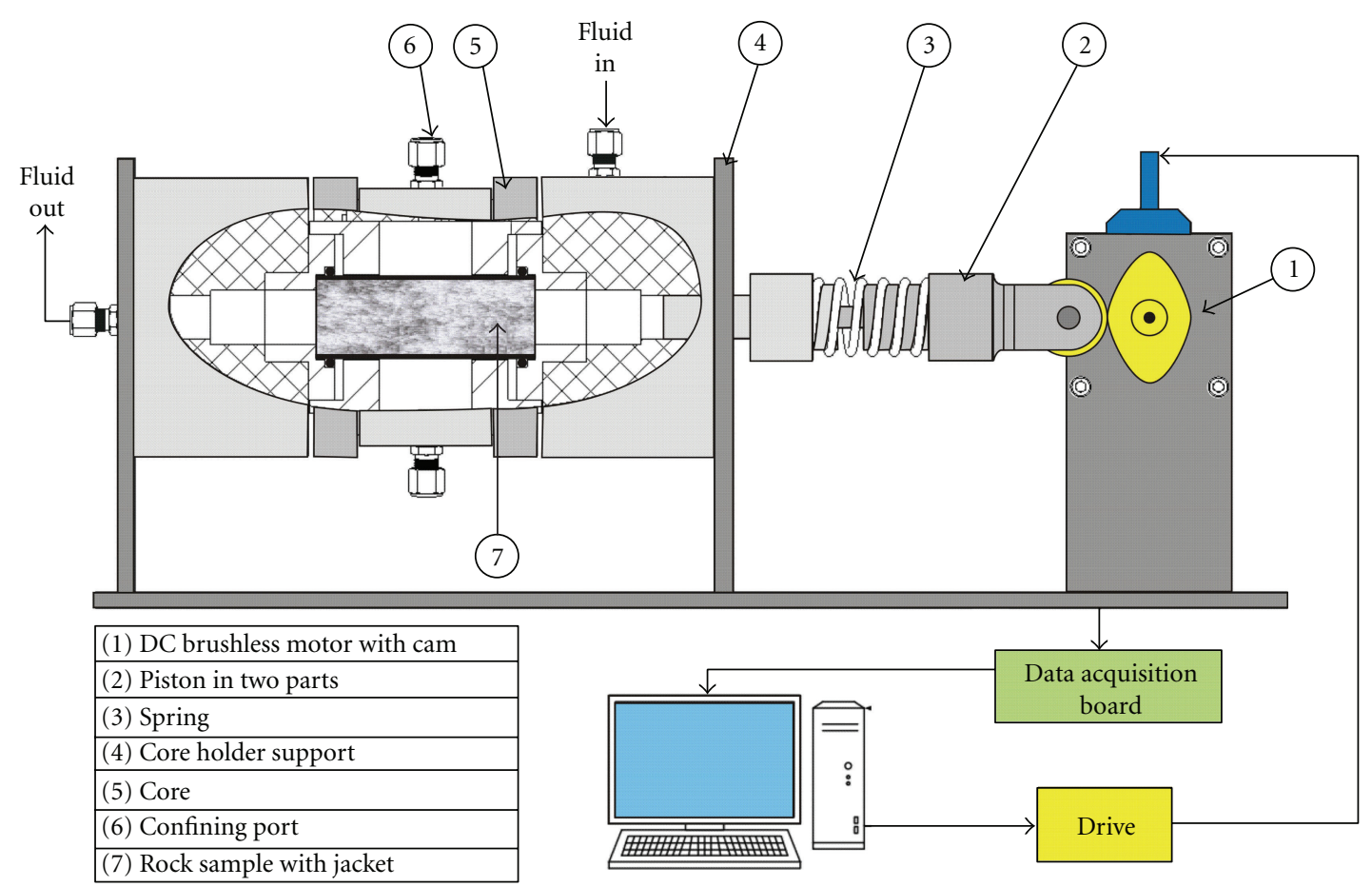

(b)

FIGURE 2: Conceptual AC electrokinetic cells with (a) connecting-pin drive and (b) cam drive. 

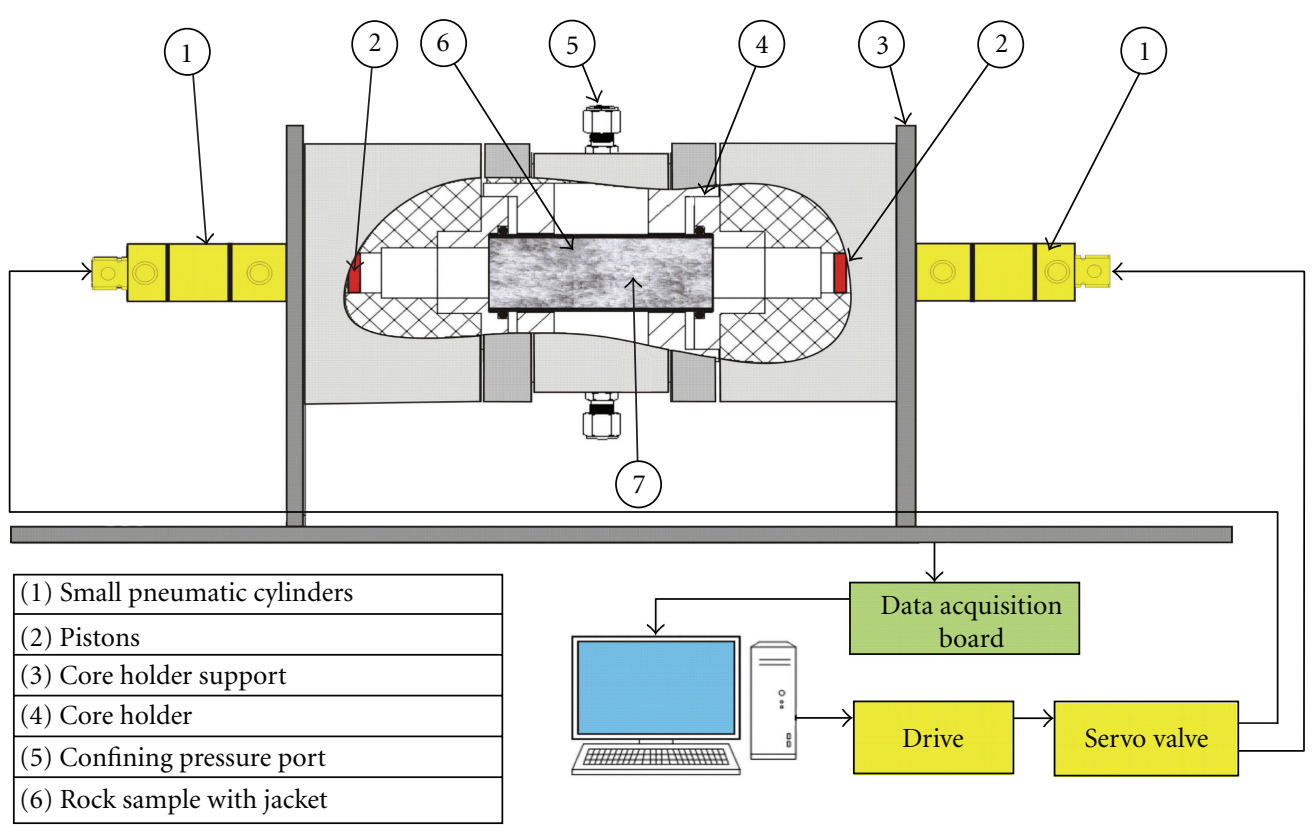

(a)

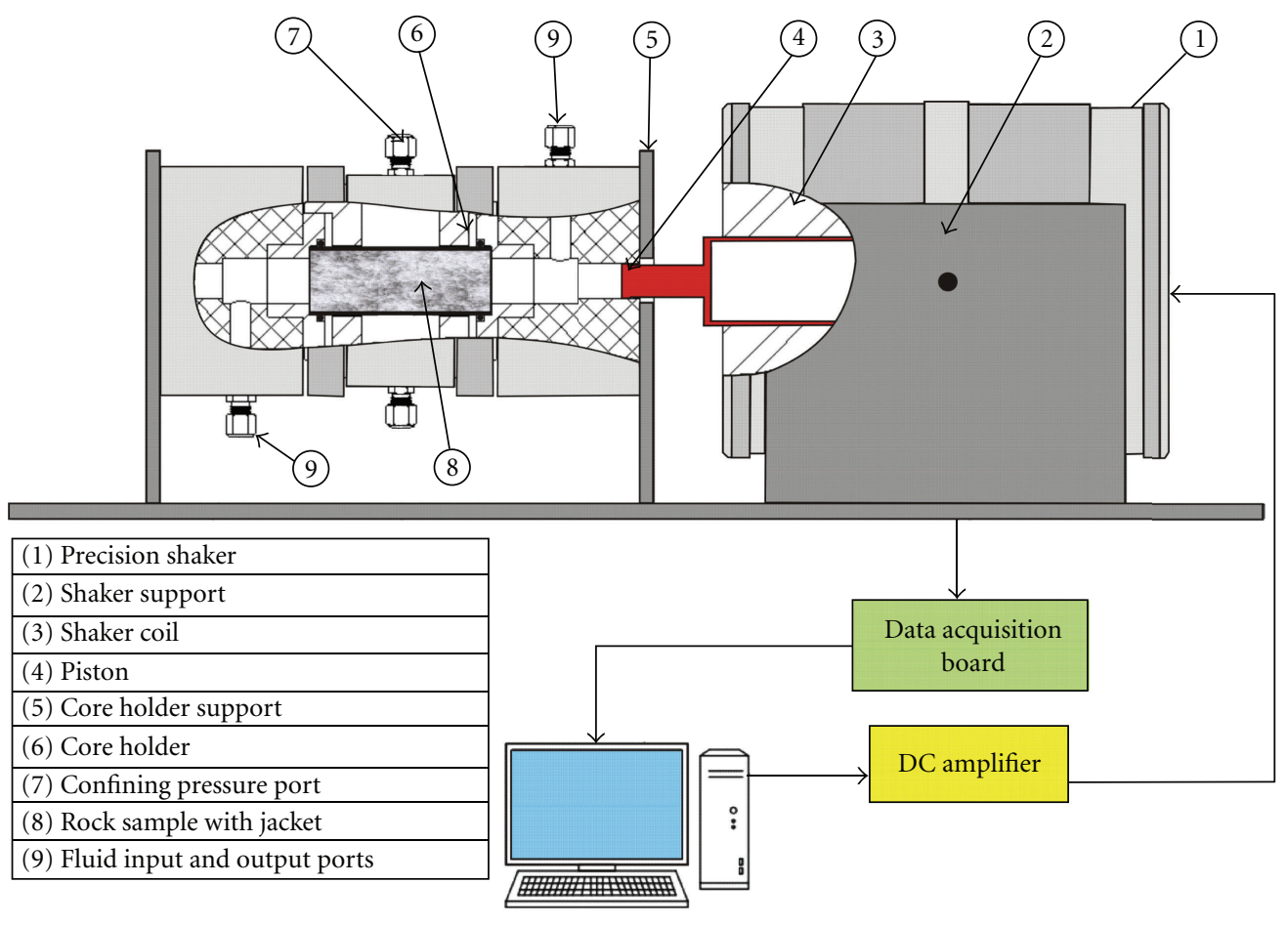

(b)

FIGURE 3: Conceptual AC electrokinetic cells with (a) pneumatic and (b) electromagnetic drive.

\section{Experimental Apparatus}

We have designed, constructed, and tested an experimental apparatus for measuring the AC streaming potential coefficient of granular materials such as sands using an electromagnetic drive. Figure 4 shows the conceptual model and image of the resulting apparatus, while Figure 5 shows more detailed drawings of its construction and an expanded view of the piston entry. We restricted ourselves to using granular materials for these tests in order to avoid constructing a sample holder where the sample is sleeved. Potentially the most complex part of the apparatus is the piston. We opted initially to use pistons from a standard $60 \mathrm{~mL}$ laboratory syringe (Figures 4 and 5). These are robust as well as being cheap and easy to replace. They have an external working diameter of $2.54 \mathrm{~cm}$ and an extremely well-designed seal. 
TABLE 2: Summary of the main characteristics and limitations of each of the drive methods. Please see the appendix for details.

\begin{tabular}{lcl}
\hline Drive method & $\begin{array}{c}\text { Maximum } \\
\text { practical frequency } \\
\text { range }(\mathrm{Hz})\end{array}$ & Comments \\
\hline Hydraulic & $0-5$ & $\begin{array}{l}\text { Design limited by } \\
\text { (i) Maximum frequency of hydraulic valves. }\end{array}$ \\
\hline $\begin{array}{l}\text { Connecting pin } \\
\text { (scotch yoke) }\end{array}$ & $0-33$ & $\begin{array}{l}\text { Design limited by } \\
\text { (i) Lack of a motor with a combination of sufficient torque and speed. } \\
\text { (ii) Lack of a spring with sufficient stiffness per mass. }\end{array}$
\end{tabular}

Design limited by

(i) Lack of a motor with a combination of sufficient torque and speed.

Cam $\quad$-33 (ii) Lack of a spring with sufficient stiffness per mass.

Advantages:

(i) Has a lower friction than the connecting pin approach, which reduces the torque that the motor must provide.

(ii) The profile of the imposed fluid pulse can be varied by changing the shape of the cam.

Design limited by

\begin{tabular}{|c|c|}
\hline Pneumatic & \\
\hline
\end{tabular}

Advantage:

(i) Does not require a spring for smooth operation because of the compressibility of the gas.

Design limited by

(i) The specification of the electromagnetic shaker used (here a VTS-100).

Electromagnetic 2-6500

(ii) Electromagnetic noise is a problem to be overcome with shielding and signal preamplification.

Advantages:

(i) Does not require a spring for stable operation due to EM damping.

(ii) Covers the range of frequencies most useful in the characterisation of sands, rocks, soils and gravels.

(iii) Control of piston displacement allows the fluid pressure to be well controlled.

Design limited by

(i) Lack of availability of transducers for frequencies less than about $200 \mathrm{~Hz}$.

(ii) It is not possible to drive a piezoelectric system at a wide range of frequencies.

(iii) The generated displacements are very small, and it is not certain that the electrokinetic effect is fully developed with such small displacements.

Piezoelectric 200-10000

(iv) It is unclear whether check valves can be made to operate effectively at such small swept volumes and high frequencies.

Advantages:

(i) Frequencies above $10 \mathrm{kHz}$ may be attained.

(ii) Covers the range of frequencies most useful in the study of seismoelectric exploration.

(iii) Forces far greater than that possible with an electromagnetic shaker are possible with a stack of piezoelectric transducers, allowing the study of low porosity, low permeability rocks at specific frequencies.

However, subsequently we have used a piston with a jointed design that is made from brass with an 'O'-ring seal. The jointed design improves the alignment and reduces seal ware.

The sample is held in a thick horizontal Perspex tube by perforated Perspex discs and a spring. There are four ports at each end of the tube. These are arranged radially with an offset of $90^{\circ}$ and can accommodate up to two nonpolarizing electrodes, a pressure transducer, and a check valve (Figure 5). The piston end of the tube is either left open to accept a piston with a rubber seal or can be covered with a rubber membrane. The output end is connected directly to the output fluid reservoir. While it is possible to raise the output fluid pressure with the aid of a backpressure regulator, the output fluid pressure was kept at atmospheric pressure for most of the initial tests. The sample tube is held extremely rigidly in a frame to which the shaker is also attached. The 


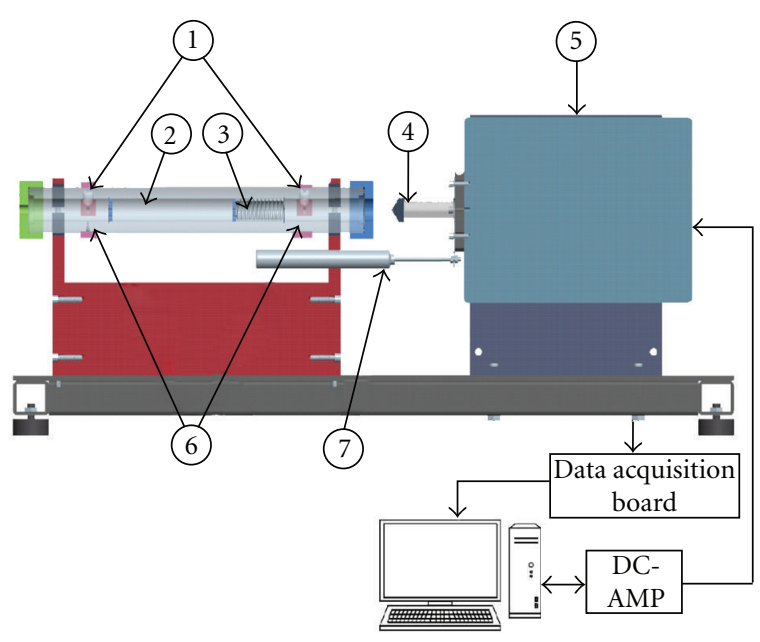

(a)

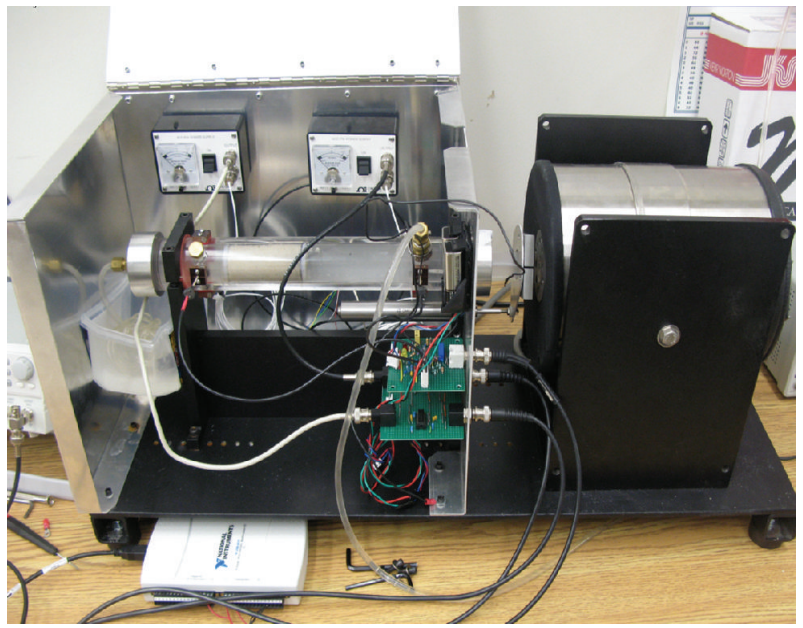

(b)

FIGURE 4: The electromagnetic drive apparatus for measuring the time-dependent streaming potential coefficient of granular media; (a) diagram, (b) photograph. (1) Port for fluid circulation or pressure transducer (2 at each end), (2) space for sample, (3) support spring and perforated end-piece, (4) piston, (5) precision electromagnetic shaker, (6) position of electrodes, and (7) linear motion sensor (LVDT).

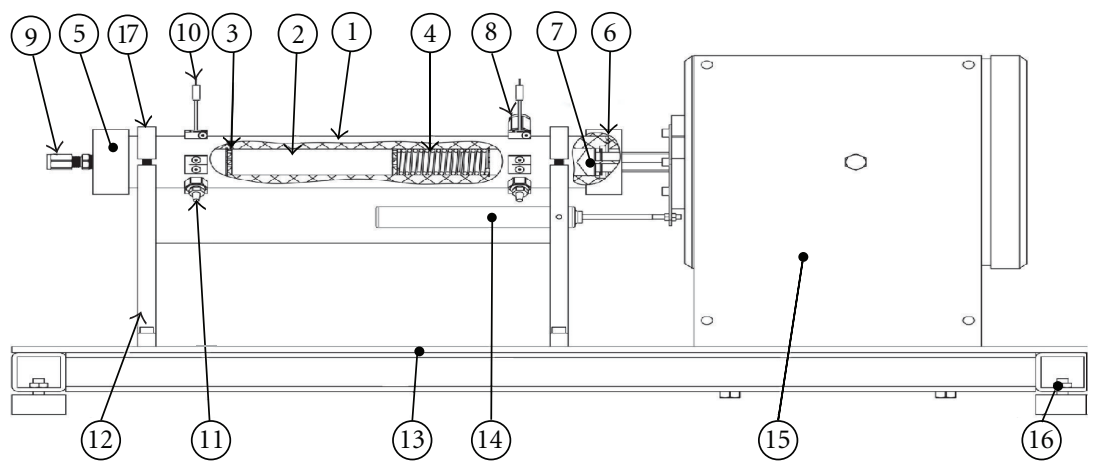

(a)

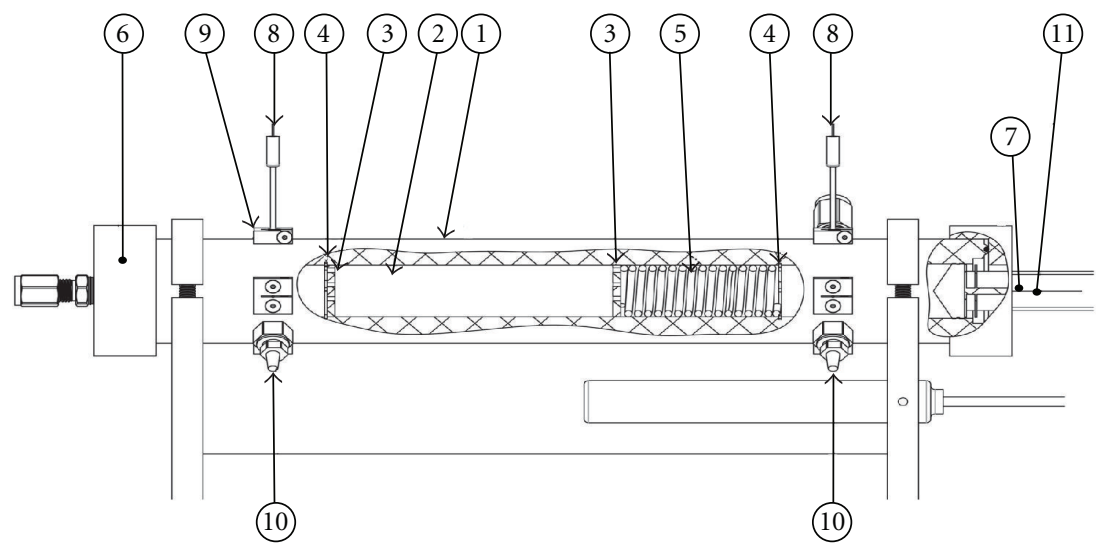

(b)

Figure 5: Detailed design of the electromagnetic drive apparatus: (a) complete, (1) perspex tube, (2) sample, (3) drilled polycarbonate disk, (4) spring, (5) screwed output end enclosure, (6) screwed input end enclosure, (7) piston, (8) fluid input check valve (Swagelok), (9) fluid output connector (Swagelok), (10) downstream streaming potential electrode, (11) downstream dynamic pressure transducer, (12) steel frame, (13) steel base, (14) LVDT, (15) EM shaker, (16) adjustable vibration damping feet, and (17) clamp to hold tube. (b) Details of the piston assembly, (1) perspex tube, (2) sample, (3) drilled polycarbonate disk, (4) circlip, (5) spring, (6) screwed output end enclosure, (7) screwed input end enclosure, $(8)$ streaming potential electrodes $(\times 2),(9)$ sealing mechanism for inserting streaming potential electrodes, (10) dynamic pressure transducers $(\times 2)$ downstream, and (11) piston. 


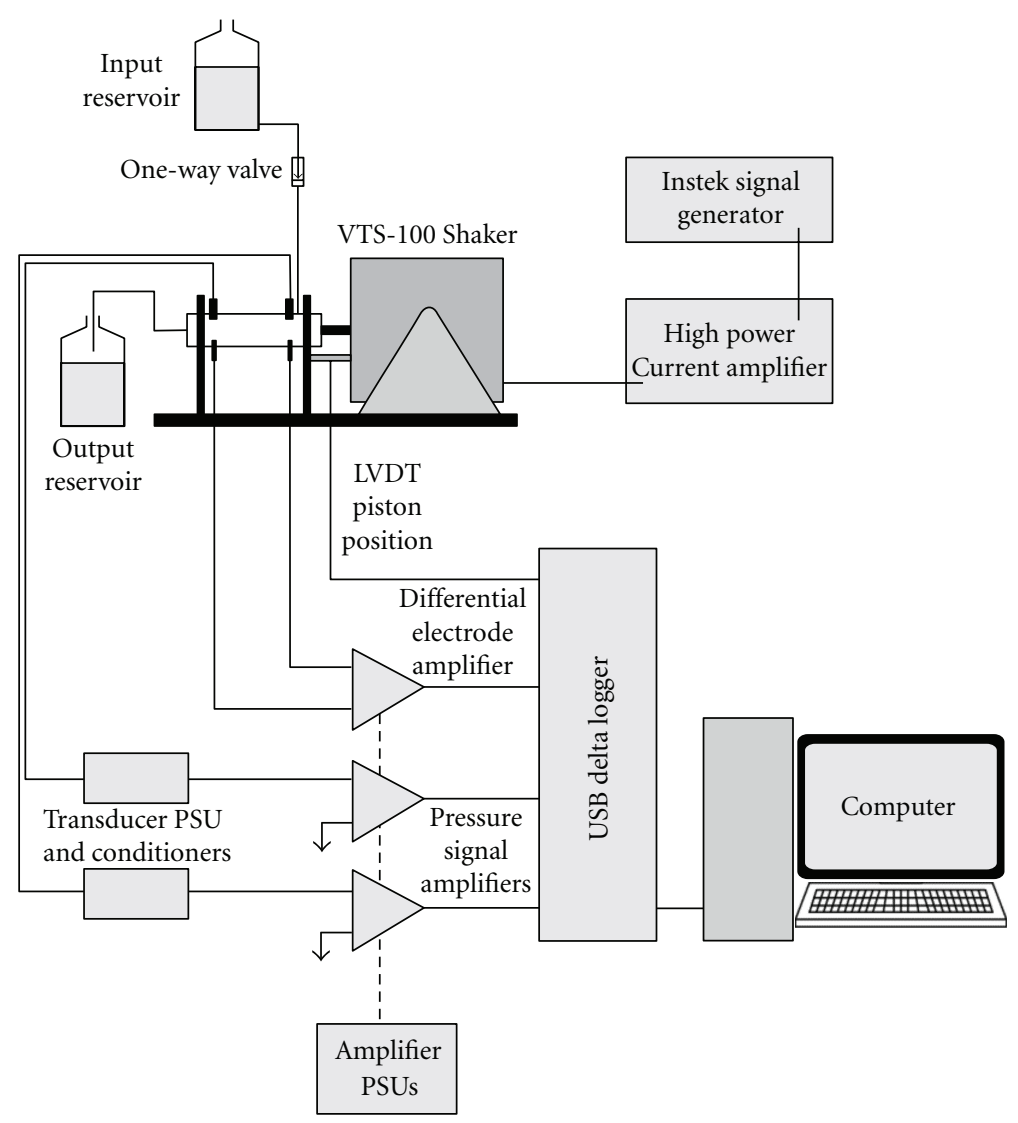

Figure 6: Experimental setup.

electromagnetic shaker drives the piston directly along the axis of the sample cell. Hence the system is conceptually and in reality extremely simple.

There are a number of different ways in which the system can be used. The drive may be imposed by the piston directly or by the piston working on the rubber membrane. There are 4 modes of fluid transport:

(a) with a closed fluid system (i.e., no fluid input or output) (push-pull AC mode);

(b) with fluid being drawn into the cell through a check valve on the backstroke of the piston and then driven through the sample on the compression stroke (pumping AC mode);

(c) while a constant fluid flow is imposed by an external pump (DC mode);

(d) a combination of (b) and (c). In this mode we have an AC signal imposed upon a DC signal, but the DC flow elevates the upstream fluid pressure sufficiently to counter any tendency to cavitation on the return stroke of the piston.

The apparatus imposes a time-varying fluid flow while measuring and logging (i) the displacement of the piston, (ii) the instantaneous pressure at each end of the sample, and (iii) the instantaneous electrical potential difference between the ends of the sample. The instantaneous streaming potential coefficient is the ratio of the electrical potential difference and the fluid pressure difference. Hence we required highquality fluid pressure and electrical potential measurements to enable accurate streaming potential coefficient measurements to be made, while an independent measurement of piston displacement was also desirable. Figure 6 shows the overall data acquisition setup, the elements of which are described below.

Fluid pressure measurements are made using DPX101250 and DPX101-5K dynamic pressure transducers from Omega. These transducers have a maximum pressure of 1.72 $\mathrm{MPa}$ (250 psi) and 34.4 MPa (5000 psi), respectively. The DPX-250 transducer allows samples up to $150 \mathrm{~mm}$ long with a diameter of $25.4 \mathrm{~mm}$, porosities up to 0.3 , and with hydraulically conductive pores greater than $33.8 \mu \mathrm{m}$ to be measured up to $1 \mathrm{kHz}$. The larger range transducer can be used if the samples are longer, have a smaller diameter, have a smaller porosity, or contain smaller pores. Shorter, more porous samples with larger pores can be measured with the DPX-250 transducer and by increasing the piston displacement. Both of these transducers are designed for measuring pressures that change at a high frequency. They have a rise time of $1 \mu \mathrm{s}$, a resonant frequency of $0.5 \mathrm{MHz}$, and can be used at frequencies up to $170 \mathrm{kHz}$. Each of the transducers is operated by a separate driver and signal conditioning unit (ACC-PS1), which can be seen in Figure 4(b) as the boxes with small panel meters. The two pressure signals are passed to two matched preamplifiers and hence to a National Instruments USB-6229 data acquisition 
system that is controlled by LabView. The preamplifiers, which were designed and constructed in our laboratory, are based on a quad low noise TL074IN J-FET input operational amplifier chip from Texas Instruments.

We have used a number of different electrodes with various degrees of success. The measurements shown in the associated paper [12] were made using nonpolarising $\mathrm{Ag} / \mathrm{AgCl}$ electrodes from Cypress Systems. However, we have also used platinum black electrodes with success. The electrical potential difference measurements are amplified using a differential preamplifier that we have designed and constructed specifically for the task. Since the resistance of rocks ranges from very low values for high porosity, highly connected rocks that are saturated with saline pore fluids to extremely high values for low porosity rocks that are saturated with low salinity fluids, we required the input impedance of the measurement circuitry to be at least $10^{9} \Omega$. The differential preamplifier we built has an input impedance of $10^{12} \Omega$ and is based on TL074IN J-FET input operational amplifier chips from Texas Instruments. These amplifiers have a slew rate of $13 \mathrm{~V} / \mu \mathrm{s}$, which is sufficient for the amplifiers to follow a signal up to $4.83 \mathrm{MHz}$. The output of the preamplifier is logged by a National Instruments USB6229 data acquisition system and controlled by LabView.

An LVDT from Omega (LD610-15) has also been incorporated in the experimental apparatus in order that the precise position of the piston can be logged together with the potential and pressure signals. This allows us to confirm that the movement of the piston is correct and may also allow us to add a control loop at some future date.

Power-line electrical noise was a problem initially, swamping the signal ( $29 \mathrm{~dB}$ with respect to the signal). The cell was enclosed in a Faraday cage as shown in Figure 4(b). In addition, the measured signals were amplified by custom designed preamplifiers that were placed close to the transducers and inside the Faraday cage. While low noise active power supplies were used to drive the preamplifiers in initial tests, they were soon replaced by batteries in order to reduce power line noise further. The combined effect of the Faraday cage and the preamplification reduced the noise by $46 \mathrm{~dB}$ so that the noise was reduced to $-17 \mathrm{~dB}$ with respect to the signal. Signal averaging is then used to reduce the final noise level to $-51 \mathrm{~dB}$ with respect to the signal.

The electromagnetic shaker is driven by its own power amplifier and controlled by a GW Instek (SFG-2110) function generator. The function generator allows the type of wave and its frequency to be defined, while the power amplifier controls the displacement of the piston and the force it can impart. The temperatures of the fluid and of the cell are also routinely measured using calibrated K-type thermocouples.

Although it is possible to calculate the instantaneous streaming potential coefficient, such data is noisy. In our data analysis we prefer to use the RMS fluid pressure difference and the RMS electrical potential difference calculated over at least 100 cycles to calculate the streaming potential coefficient. This method provides a robust and accurate value for the streaming potential coefficient. We are currently examining ways of using active digital filtering to improve the quality of the data by removing harmonic noise from the data, but since this is a paper concerned with mechanical and experimental design, we will report our data processing advances elsewhere. However, there does exist an excellent article on the collection and processing of streaming potential data by Reppert and Morgan [4].

\section{Conclusions}

Six different approaches to the design of an experimental apparatus for measuring the time-dependent streaming potential coefficient of porous and granular media have been examined. There are fundamental or practical limitations to five of them.

A hydraulic drive was eliminated at an early stage due to the difficulty of driving liquids at high frequencies. The connecting pin and spring (scotch yoke) approach is first constrained to $f<125 \mathrm{~Hz}$ by the spring design, and then to $f<33 \mathrm{~Hz}$ by the lack of an electric motor with sufficient torque and speed. This design has been used once in the past but only in the range $f<21.28 \mathrm{~Hz}$ [7]. The cam and spring design is similar being first constrained to $f<125 \mathrm{~Hz}$ by the spring design, and then to $f<33 \mathrm{~Hz}$ by the electric motor specification. The pneumatic drive approach is constrained to $f<100 \mathrm{~Hz}$ by the maximum frequency of commercially available servovalves, while the use of a piezoelectric drive has a number of disadvantages, the most serious of which are that they can only be used for $f>200 \mathrm{~Hz}$ and for a very small range of frequencies.

The most promising approach was that of using an electromagnetic drive, which can, in principle, provide a measurement in the range $1 \mathrm{~Hz}<f<6.5 \mathrm{kHz}$ (using a VTS100 shaker) with accurate frequency and amplitude control. This approach was implemented as a full experimental rig for samples of disaggregated and unconsolidated porous media such as sands. The apparatus can take samples with a diameter of $2.54 \mathrm{~cm}$ that are packed into a Perspex tube. Sample lengths between 5 and $30 \mathrm{~cm}$ are possible. We have tested the apparatus successfully and give some initial data in an associated paper [12]. Since the differential fluid pressure depends strongly on the porosity and permeability of the sample and solid samples require a pressure vessel with a sample sleeve, we have developed a separate apparatus for solid samples of porous media including rocks, which is in development. Early results from this apparatus suggest that cavitation is a problem that needs to be overcome using some method other than check valves.

\section{Appendix}

\section{A. Analysis of Drive Mechanisms}

In the following analyses we assume that the sample and piston diameters are equal and in the range 5 to $40 \mathrm{~mm}$. This implies that the force that the piston must impart to the fluid is in the range $39.27 \mathrm{~N}$ to $2513 \mathrm{~N}$ in order to obtain a maximum fluid differential pressure of $2 \mathrm{MPa}$. 
A.1. Connecting-Pin Drive. A conceptual design for an AC electrokinetic apparatus using a connecting-pin drive is shown in Figure 2(a). The driving force is provided by an electric motor and a system of connecting pins and springs. The motor drives a wheel upon which an eccentred pin has been attached. The rotation of the motor is transformed into a linear motion by the action of the eccentred pin (Figure 2(a) (1)) within a slot in the scotch yoke rod (Figure 2(a) (2)). The linear movement compresses a spring Figure 2(a) (3), which is calibrated to require $160 \mathrm{~N}$ for each $1 \mathrm{~cm}$ of compression. The spring acts upon the compression piston Figure 2(a) (4) in such a manner that a maximum pressure can be applied to the pore fluid. The spring is necessary to allow the motor to turn while using low porosity samples with an incompressible pore fluid, which would otherwise lock up the mechanism.

Assuming that the sample and piston diameter falls in the range $5<d_{p}<40 \mathrm{~mm}$, the spring constant $k_{\mathrm{sp}}$ required to generate a maximum pore fluid pressure $P_{\max }=$ $2 \mathrm{MPa}$ with a piston displacement of $1 \mathrm{~cm}$ falls in the range $3.93 \times 10^{3} \mathrm{~N} / \mathrm{m}<k_{\mathrm{sp}}<2.51 \times 10^{5} \mathrm{~N} / \mathrm{m}$. This type of spring is commercially available. The mean flow rate varies between $0.39 \mathrm{~cm}^{3}$ per cycle and $25.13 \mathrm{~cm}^{3}$ per cycle. It is also necessary to calculate the maximum frequency that such a system could reach while remaining stable. We have used the equations in Juvinall and Marshek [20] to obtain the natural frequency $f_{n}=198 \mathrm{~Hz}$ for spring with dimensions conforming to our experimental design $(5.55 \mathrm{~cm}$ diameter spring). Such a spring is stable only if the 13th harmonic of the mechanical system is smaller than $f_{n}$, which implies that the maximum drive frequency we could use is $15.23 \mathrm{~Hz}$ using this drive method. If we use the smallest spring and sample combination possible ( $5 \mathrm{~mm}$ diameter) the highest stable frequency is $125 \mathrm{~Hz}$.

In order to reach frequencies of $1 \mathrm{kHz}$ we need a motor that will be capable of a speed of 60,000 revolutions per minute (rpm). Knowing the forces that must be overcome in order to turn the drive wheel allows us to calculate the specifications of the motor. If the distance between the centre of the connecting pin and the motor axis is $B$, the force experienced by the connecting pin is given by $F=m B \omega^{2} \sin (\omega t)+k_{\mathrm{sp}} B \sin (\omega t)$, where $m$ is the mass of the piston, spring, and connecting pin (i.e., those parts that are moved by the connecting wheel) and $\omega$ is the angular frequency. This equation assumes that damping in this system is negligible, which is reasonable if the sample is fully saturated with a noncompressible fluid. However, if the sample is not fully saturated, there is a damping term of the form $B \omega \cos (\omega t)$. The force $F$ creates a torque due to its tangent component and the tangent component of the resulting friction force which operates between the surface of the connecting pin and the inner surface of the slot in the connecting pin. The motor must develop a torque that is sufficient to compress the spring and accelerate the masses. It must therefore develop a torque given by $M=F B \cos (\omega t)+$ $F \mu B \sin (\omega t)$, where $\mu$ is the coefficient of friction, which leads to $M=\left(B^{2} / 2\right)\left(m \omega^{2}+k_{\mathrm{sp}}\right)(\mu+\sin (2 \omega t)-\mu \cos (2 \omega t))$, and where the frequency of the torque $M$ is twice that of the force. The torque is zero at $2 n \pi / 4$, where $n$ is an integer (including zero), but does not reach its maxima at $(2 n+1) \pi / 4$ because the torque is not symmetrical but reaches its maximum value at about $0.84 \mathrm{rad}$ (about 48 degrees). One should note that the position of the maximum value is not a function of $m$, $k_{\mathrm{sp}}, \omega$, or $B$, but does depend upon the coefficient of friction $\mu$.

Figure 7(a) shows the maximum torque that needs to be overcome to drive a connecting pin design as a function of frequency for different values of coefficient of friction and for $\left(m=0.5 \mathrm{~kg}, k_{\mathrm{sp}}=1.6 \times 10^{4} \mathrm{~N} / \mathrm{m}, \omega=6283 \mathrm{rad} / \mathrm{s}(1000 \mathrm{~Hz})\right.$, $B=1 \mathrm{~cm})$. It is clear that a well-lubricated system is needed to reduce the coefficient of friction to as low a value as possible. The value of the coefficient of friction also governs when in the cycle of the motor the maximum torque is attained (Figure 7(b)). For the scenario shown in Figure 7, the value of the maximum torque is about $1090 \mathrm{Nm}$. We have found that commercially available electric motors that can operate at the required speed are not able to provide a torque this high, not even close. Furthermore, reducing the piston diameter to $5 \mathrm{~mm}$ only provides a marginal reduction in the maximum torque that needs to be overcome. Indeed, if we relax the frequency specification to that which would be possible with the spring system, we obtain a torque of $17.04 \mathrm{Nm}$. It is possible to find brushless motors that can provide such a torque, but only for speeds up to about $2000 \mathrm{rpm}$ (i.e., about $33 \mathrm{~Hz}$ ).

In conclusion, neither an electric motor with a combination of sufficient torque and speed, nor a spring with sufficient stiffness per mass is currently available for the connecting-pin design to be feasible up to $1 \mathrm{kHz}$. Such a system would be possible, but could attain frequencies only up to about $33 \mathrm{~Hz}$ with current technology. Indeed, Sears and Groves [7] who used such a system were only able to attain a maximum frequency of $21.28 \mathrm{~Hz}$.

A.2. Cam Drive. A conceptual design for an AC electrokinetic apparatus using a cam drive is shown in Figure 2(b). This mechanical system works in a similar manner to the connecting-pin design. The motor turns a cam with a variable diameter. The cam acts on a wheel which is attached to a pin that compresses a spring in the same manner as for the connecting-pin design. The spring has the same purpose as in the connecting pin design, but also acts to maintain good contact between the wheel and the spring. The main advantage of the cam mechanism is that it has a lower friction, which reduces the torque that the motor must provide. A secondary advantage is that the profile of the imposed fluid pulse can be varied by changing the shape of the cam.

Many of the same design considerations that were made for the connecting pin design are also valid for this design. The lack of a spring with a sufficiently high natural frequency makes the design unworkable above about $125 \mathrm{~Hz}$. The lower internal friction of the design (approaching 0.01) reduces the torque required by the motor to about $997 \mathrm{Nm}$. However, this is, once more, much higher than electric motors of a modern design can provide. At $125 \mathrm{~Hz}$, the torque is $15.57 \mathrm{Nm}$, which again can be reached by brushless motors but only for frequencies up to about $33 \mathrm{~Hz}$. 


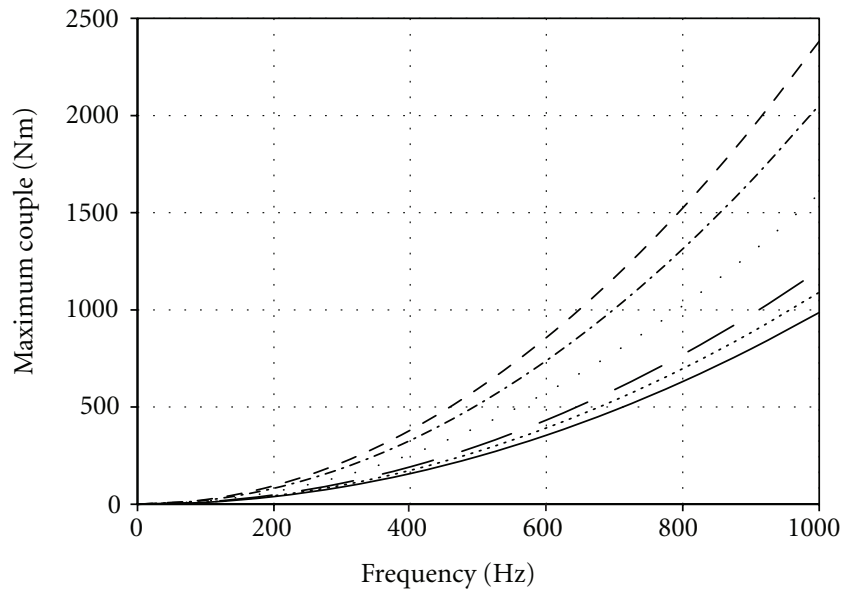

Coefficient of friction

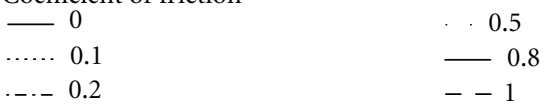

(a)

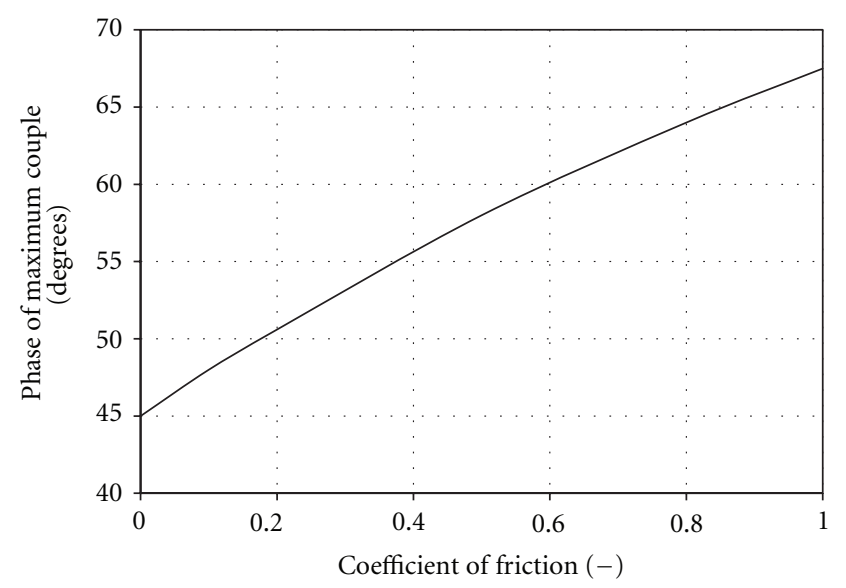

(b)

Figure 7: (a) The maximum torque that needs to be overcome to drive a connecting pin design as a function of frequency for different values of coefficient of friction. (b) The phase at which the maximum torque occurs as a function of the coefficient of friction.

A.3. Pneumatic Drive. A conceptual design for an AC electrokinetic apparatus using a pneumatic drive is shown in Figure 3(a). The pneumatic system consists of two small actuators that are situated on each side of the sample vessel. We consider a mode of operation where the actuators are controlled in extension and allowed to retract under the influence of the fluid pressure in the cell (i.e., neutral mode). This mode of operation decreases both the response time and fluid friction in the pipes, but requires there to be an actuator at each side of the sample in order to complete the full cycle. The two-actuator approach also allows an external reservoir to be eliminated, while using the space that is occupied by the piston in the other designs to act as an internal fluid reservoir. In order to impose a sinusoidal fluid pressure in the process fluid, a rectified half-wave is first sent to the servo-valve controlling the first actuator, while the other actuator is subject to atmospheric pressure. When the first rectified half-wave returns to zero (i.e., atmospheric pressure), a rectified halfwave is sent to the servo-valve controlling the second actuator, while the first actuator is subject to atmospheric pressure.

The advantage of the pneumatic system is that the air is compressible. The compressible air allows the imposition of the force without the need for a spring, which eliminates the frequency limit that was caused by the springs in the mechanical designs. A variation on this design might replace both actuators with membranes that are activated by pneumatic pressure. Such a design has the potential to reach higher frequencies still. We have calculated that if a standard $100 \mathrm{psi}(689 \mathrm{kPa})$ pneumatic system is used, the diameter of the actuator needs to be between $0.85 \mathrm{~cm}$ and $6.81 \mathrm{~cm}$ in order to generate a maximum fluid pressure of $2 \mathrm{MPa}$. Although actuators with this diameter are available, the servo-valve would have to operate at very high speeds in order to attain a frequency of $1 \mathrm{kHz}$. Presently the fastest available servovalves only allows speeds up to $100 \mathrm{~Hz}$ to be reached. Hence, a pneumatic system is currently not possible above about $100 \mathrm{~Hz}$.

A.4. Electromagnetic Drive. A conceptual design for an AC electrokinetic apparatus using a electromagnetic drive is shown in Figure 3(b). The electromagnetic drive system relies on the use of an electromagnetic shaker. Such shakers provide high-quality sinusoidal displacements at low or high frequencies. Their main use is in the testing of mechanical structures and aircraft. A sine wave generator is used to drive a DC amplifier which provides an amplified current sufficient to drive the electromagnetic shaker. This current passes through the coils of the shaker producing an electromagnetic field which in turn displaces a magnetic rod. The force on the rod is proportional to the current. The rod (Figure 3(b) (4)) is attached to a piston that drives the fluid through the sample with a sinusoidally varying force. Two one-way valves are arranged at each end of the sample to allow new fluid to be drawn into cell on the return stroke which is then pushed through the sample on the compression stroke. The result is a sinusoidally varying fluid pressure during the compression stroke, and a quasisinusoidally varying fluid pressure during the return stroke. There are a range of different shakers available, some of which have maximum frequencies of the order of $4500 \mathrm{~Hz}$, rod displacements up to $50 \mathrm{~mm}$, and maximum forces ranging from $100 \mathrm{~N}$ to $178000 \mathrm{~N}$.

It is possible to control the piston displacement of a shaker by varying the control current. However there exists a maximum displacement which decreases with frequency. We need to ensure that the maximum piston displacement at $1 \mathrm{kHz}$ is sufficient to make high-quality measurements. The force provided by a shaker is given classically by $F=$ $F_{o} \sin (\omega t)=m a$, where $F_{o}$ is the maximum force that the shaker can provide, $m$ is the mass of fluid accelerated at an acceleration $a, \omega$ is the angular frequency, and $t$ is time. The acceleration $a$, velocity $v$, and displacement $x$ of the shaker rod (and any piston that is attached to it) can be obtained by rearrangement and integration of the force equation to give $a=F_{o} \sin (\omega t) / m ; v=F_{o} \cos (\omega t) / m \omega ; x=$ $-F_{o} \sin (\omega t) / m \omega^{2}$. For a typical shaker such as the one we 
have subsequently used (Dynamic solutions, VTS-100) $F_{o}=$ $100 \mathrm{lbf}(444.82 \mathrm{~N})$, which easily supplies the force required to generate a fluid pressure difference of $2 \mathrm{MPa}$ for samples with diameters in the range 5 to $40 \mathrm{~mm}$ (i.e., $39.27 \mathrm{~N}$ to $2513 \mathrm{~N}$, resp.). For an accelerated mass $m=0.5 \mathrm{~kg}$ and a frequency of $1 \mathrm{kHz}$, these applied forces imply a maximum peak-topeak displacement that varies between $4 \mu \mathrm{m}$ and $0.254 \mathrm{~mm}$ for sample and piston diameters of 0.5 and $4 \mathrm{~cm}$, respectively, and the volume of fluid moved by the shaker varies between $0.628 \mathrm{~cm}^{3} / \mathrm{s}$ and $39.9 \mathrm{~cm}^{3} / \mathrm{s}$ for sample and piston diameters of 0.5 and $4 \mathrm{~cm}$, respectively.

If we use (5) with the range of peak-to-peak displacement values $\left(4 \times 10^{-6} \mathrm{~m}<x<2.54 \times 10^{-4} \mathrm{~m}\right)$ for typical clastic rocks with porosities in the range $0.05<\phi<0.3$, with characteristic pore sizes in the range $3 \times 10^{-6} \mathrm{~m}<r_{\text {eff }}<$ $1 \times 10^{-3} \mathrm{~m}$ we generate maximum fluid pressures in the range measureable by a DPX101-5K transducer for frequencies in the range $2<f<1000 \mathrm{~Hz}$ if the samples are between 0.5 and $2 \mathrm{~cm}$ long. Repeating this analysis for typical sands and gravels with porosities in the range $0.25<\phi<0.5$ and characteristic pore sizes in the range $1 \times 10^{-5} \mathrm{~m}<r_{\text {eff }}<$ $1 \times 10^{-3} \mathrm{~m}$ generates fluid pressures in the range measureable by a DPX101-250 transducer for frequencies in the range $2<f<1000 \mathrm{~Hz}$ if the samples are between $30 \mathrm{~mm}$ and $100 \mathrm{~mm}$ long.

Figure 8 shows the maximum piston displacement and maximum piston velocity. The maximum piston acceleration is not a function of frequency and takes values of 1472, 640, 320,213 and $160 \mathrm{~m} / \mathrm{s}^{2}$ for masses of $0.1,0.25,0.5,0.75$, and $1 \mathrm{~kg}$, respectively. The thresholds shown in the diagram represent the maximum values possible using a VTS-100 Shaker from Dynamic Solutions Inc. For a mass of $100 \mathrm{~g}$ the acceleration of $1472 \mathrm{~m} / \mathrm{s}^{2}$ also represents the maximum value possible with this instrument. The displacement can be controlled by varying the current in the coils of the shaker, either manually, or using a feedback mechanism. Hence, it is possible to limit the displacement and the velocity of the piston to values that are less than the threshold values for the shaker, but still sufficient to drive the fluid through the sample.

We conclude that the electromagnetic drive has the power to drive the AC electrokinetic system up to $1 \mathrm{kHz}$. However, at low frequencies the piston displacement must be limited to ensure that it, and the piston velocity, do not reach the maximum values specified for the shaker.

A.5. Piezoelectric Drive. The last conceptual possibility is to use a piezoelectric drive to attain the required frequencies. It is certain that piezoelectric transducers can be used at the specified maximum frequency. However, they suffer from a number of practical disadvantages.

(1) It is difficult to drive a piezoelectric system at a wide range of frequencies.

(2) It is impossible to carry out tests at low frequencies (less than about $200 \mathrm{~Hz}$ ).

(3) The displacements are very small, and it is not certain that the electrokinetic effect is fully developed with such small displacements.

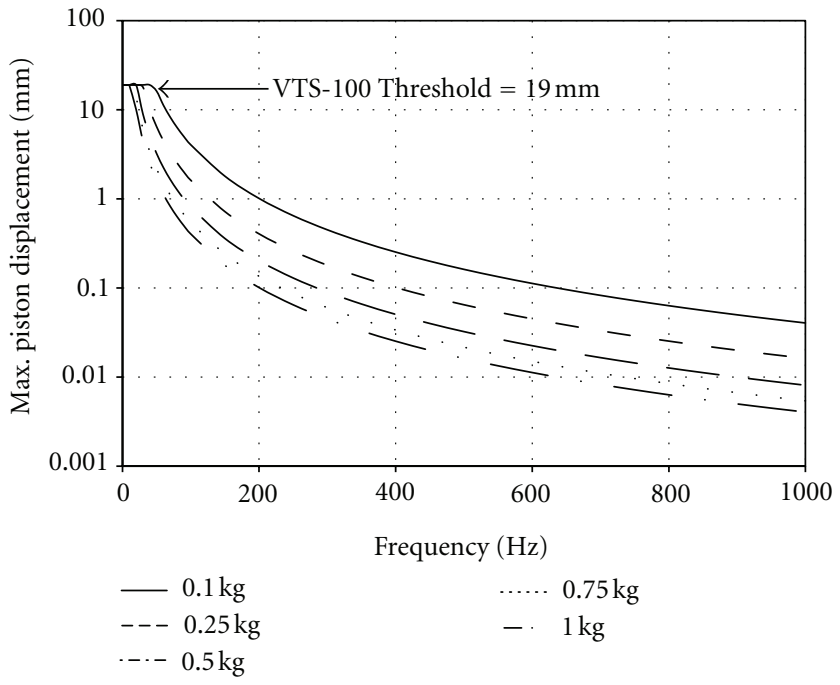

(a)

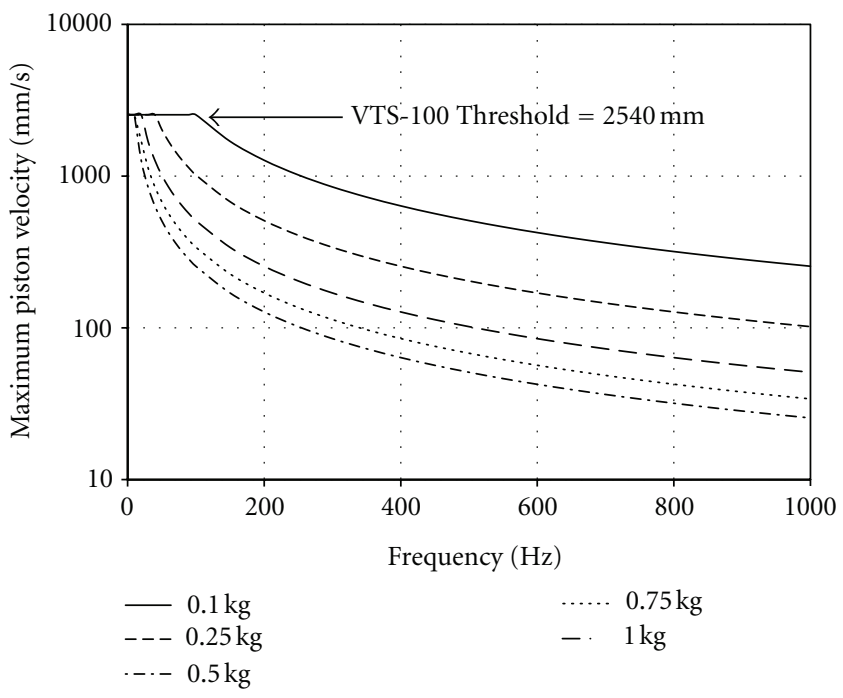

(b)

Figure 8: Dynamic properties of a system powered by an electromagnetic shaker, with a sample and piston diameter of $1 \mathrm{~cm}$ and a maximum fluid pressure of $2 \mathrm{MPa}$. (a) Maximum piston displacement as a function of frequency and driven mass. (b) Maximum piston velocity as a function of frequency and driven mass.

Consequently, we have not pursued the piezoelectric drive. However, we do recognize that the force that a stack of piezoelectric transducers can impose is far greater than that possible with a shaker, and consequently useful for low porosity and permeability rocks. Moreover, there is no reason why measurements might not be made up to far higher frequencies (above $10 \mathrm{kHz}$ ).

\section{Acknowledgments}

This work has been made possible thanks to funding by the Natural Sciences and Engineering Research Council of Canada (NSERC) Discovery Grant Programme. The 
authors would also like to thank Guillaume Lalande and the members of the mechanical engineering workshop for their help.

\section{References}

[1] C. Bordes, L. Jouniaux, S. Garambois, M. Dietrich, J. P. Pozzi, and S. Gaffet, "Evidence of the theoretically predicted seismomagnetic conversion," Geophysical Journal International, vol. 174, no. 2, pp. 489-504, 2008.

[2] C. Bordes, L. Jouniaux, M. Dietrich, J. P. Pozzi, and S. Garambois, "First laboratory measurements of seismo-magnetic conversions in fluid-filled Fontainebleau sand," Geophysical Research Letters, vol. 33, no. 1, Article ID L01302, 2006.

[3] R. Chandler, "Transient streaming potential measurements on fluid-saturated porous structures: an experimental verification of Biot's slow wave in the quasi-static limit," Journal of the Acoustical Society of America, vol. 70, no. 1, pp. 116-121, 1981.

[4] P. M. Reppert and F. D. Morgan, "Streaming potential collection and data processing techniques," Journal of Colloid and Interface Science, vol. 233, no. 2, pp. 348-355, 2001.

[5] R. G. Packard, "Streaming potentials across glass capillaries for sinusoidal pressure," The Journal of Chemical Physics, vol. 21, no. 2, pp. 303-307, 1953.

[6] C. E. Cooke, "Study of electrokinetic effects using sinusoidal pressure and voltage," The Journal of Chemical Physics, vol. 23, no. 12, pp. 2299-2303, 1955.

[7] A. R. Sears and J. N. Groves, "The use of oscillating laminar flow streaming potential measurements to determine the zeta potential of a capillary surface," Journal of Colloid And Interface Science, vol. 65, no. 3, pp. 479-482, 1978.

[8] P. M. Reppert, Electrokinetics in the earth, Ph.D. thesis, Massachusetts Institute of Technology, 2000.

[9] P. M. Reppert, F. D. Morgan, D. P. Lesmes, and L. Jouniaux, "Frequency-dependent streaming potentials," Journal of Colloid and Interface Science, vol. 234, no. 1, pp. 194-203, 2001.

[10] D. B. Pengra, S. X. Li, and P. Z. Wong, "Determination of rock properties by low-frequency AC electrokinetics," Journal of Geophysical Research B, vol. 104, no. 12, pp. 29485-29508, 1999.

[11] M. R. Sheffer, P. M. Reppert, and J. A. Howie, "A laboratory apparatus for streaming potential and resistivity measurements on soil samples," Review of Scientific Instruments, vol. 78, no. 9, Article ID 094502, 2007.

[12] P. W. J. Glover, J. Ruel, and E. Tardif, "Frequency-dependent streaming potential of porous media: 2. Experimental measurement of unconsolidated materials," International Journal of Geophysics. In press.

[13] D. L. Johnson, J. Koplik, and R. Dashen, "Theory of dynamic permeability and tortuosity in fluid-saturated porous media," Journal of Fluid Mechanics, vol. 176, pp. 379-402, 1987.

[14] Y. Bernabé, "The frequency dependence of harmonic fluid flow through networks of cracks and pores," Pure and Applied Geophysics, vol. 149, no. 3, pp. 489-506, 1997.

[15] Y. Bernabé, "Oscillating flow of a compressible fluid through deformable pipes and pipe networks: wave propagation phenomena," Pure and Applied Geophysics, vol. 166, no. 5-7, pp. 969-994, 2009.

[16] Y. Bernabé, "Propagation of Biot slow waves in heterogeneous pipe networks: effect of the pipe radius distribution on the effective wave velocity and attenuation," Journal of Geophysical Research B, vol. 114, no. 11, Article ID B11202, 2009.
[17] E. Charlaix, A. P. Kushnick, and J. P. Stokes, "Experimental study of dynamic permeability in porous media," Physical Review Letters, vol. 61, no. 14, pp. 1595-1598, 1988.

[18] E. Walker and P. W. J. Glover, "Characteristic pore size, permeability and the electrokinetic coupling coefficient transition frequency in porous media," Geophysics, vol. 75, no. 6, pp. E235-E246, 2010.

[19] E. Tardif, P. W. J. Glover, and J. Ruel, "Frequency-dependent streaming potential of Ottawa sand," Journal of Geophysical Research B, vol. 116, no. 4, Article ID B04206, 2011.

[20] K. M. Juvinall and R. C. Marshek, Fundamentals of Machine Component Design, John Wiley \& Sons, New York, NY, USA, 2005. 

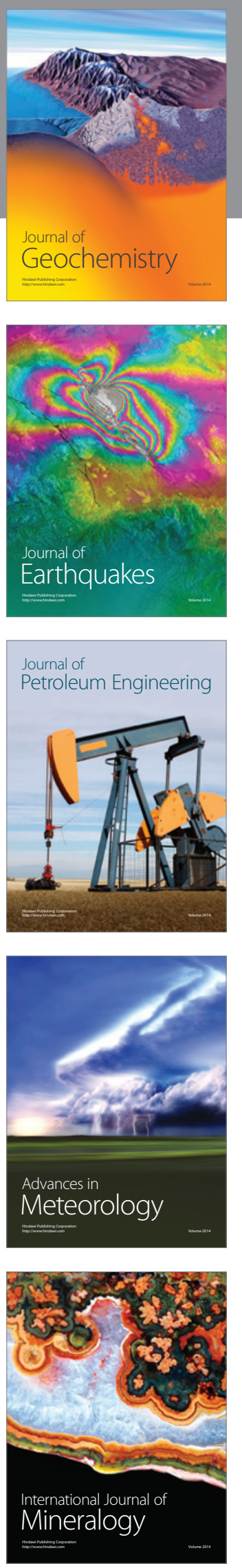
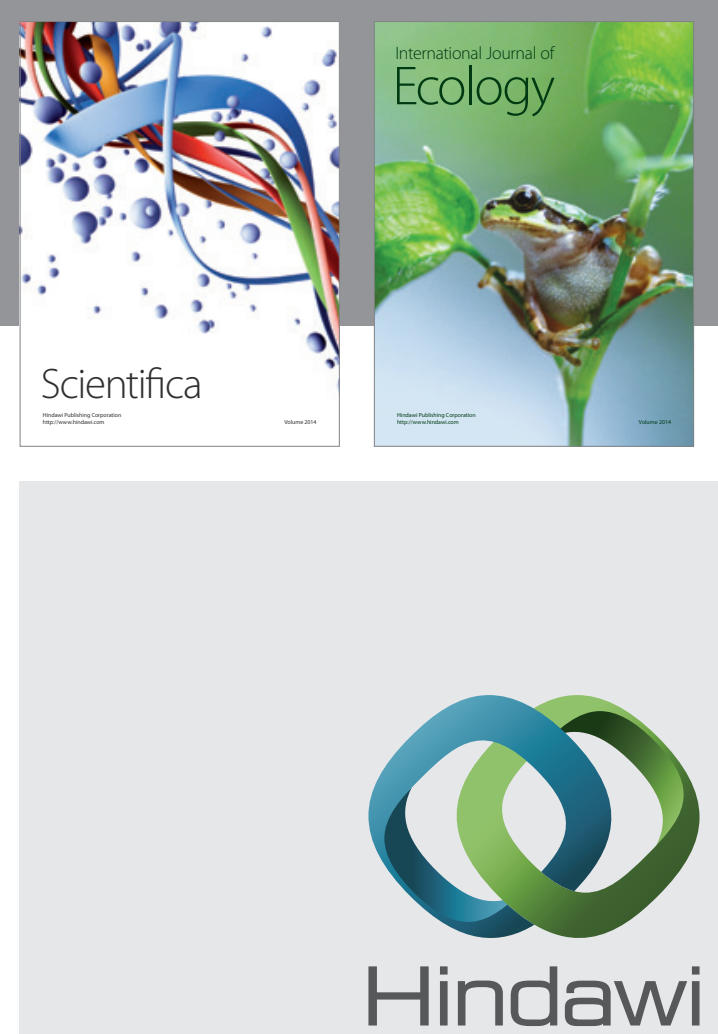

Submit your manuscripts at http://www.hindawi.com
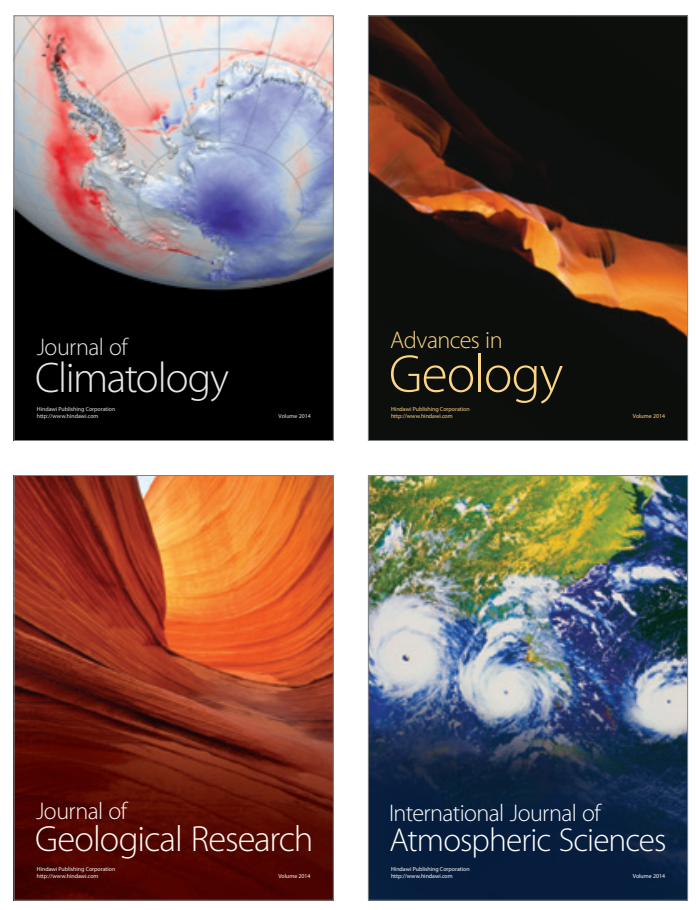
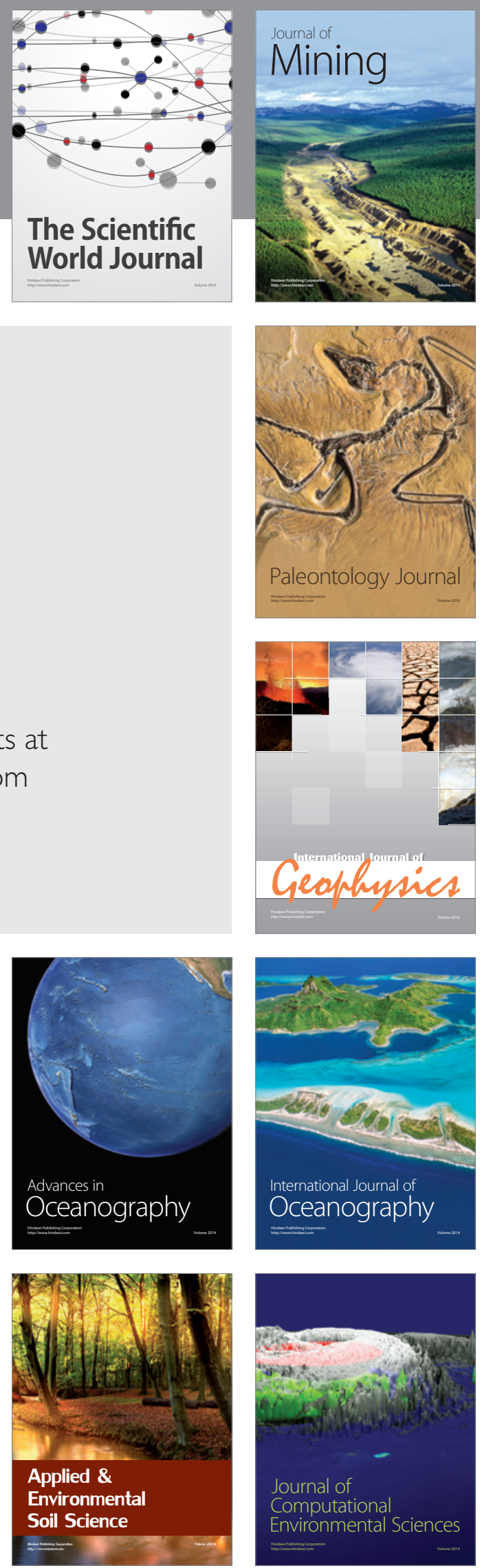